\title{
Utilizarea ecografiei cu substanță de contrast în diagnosticul refluxului vezico-ureteral la copil - prezentare de caz şi date din literatură
}

\author{
Maria Oana Mărginean', Carmen Duicu',2, Vlăduț Săsăran', \\ Cristina Oana Mărginean ${ }^{1,2}$, Lorena Elena Meliț1,2 \\ ${ }^{1}$ Universitatea de Medicină şi Farmacie, Târgu Mureş, România \\ ${ }^{2}$ Clinica de Pediatrie 1, Târgu Mureş, România
}

\begin{abstract}
REZUMAT
Refluxul vezico-ureteral reprezintă refluarea conținutului vezicii urinare în ureter şi sistemul pelocaliceal cu dilatarea consecutivă a acestora. Majoritatea cazurilor de infecție de tract urinar la copil se asociază cu reflux vezico-ureteral. Prezentăm cazul unei paciente în vârstă de 3 ani, cu multiple infecții de tract urinar simptomatice în antecedente care s-a internat în clinica noastră pentru investigații de specialitate şi stabilirea unei conduite terapeutice adecvate. Examenul obiectiv şi analizele de laborator nu au evidențiat elemente patologice. Ecografia abdominală nativă a fost fără modificări, în timp ce ecografia abdominală cu substanță de contrast a evidențiat reflux vezico-uereteral bilateral. Scintigrafia renală cu DMSA a arătat hipofuncție renală dreaptă, de $39 \%$, cu duplicitate a sistemului colector şi moderată dilatație a pielonului superior şi funcție normală a rinichiului stâng. Recomandările au constant în chimioprofilaxie pe termen lung, ecografie cu substanță de contrast anual şi monitorizare nefrologică o dată la 6 luni. Particularitatea cazului constă în diagnosticarea unui reflux vezico-ureteral bilateral prin ecografie cu substanță de contrast la o pacientă cu multiple infecții de tract urinar în antecedente, la care ecografia renală nativă nu a evidențiat modificări patologice.
\end{abstract}

Cuvinte cheie: infecție urinară, reflux vezico-ureteral, SonoVue®, copil

\section{INTRODUCERE}

Refluxul vezico-ureteral reprezintă refluarea conținutului vezicii urinare în ureter şi sistemul pielocaliceal cu dilatarea consecutivă a acestora. Una dintre complicațiile majore care poate surveni în cazul pacienților diagnosticați cu reflux vezicoureteral este reprezentată de recurența infecțiilor urinare de tip înalt. De altfel, de cele mai multe ori diagnosticul refluxului vezico-ureteral şi a hidronefrozei subsecvente este o consecință a evaluării de rutină în cazul unei infecții de tract urinar de tip înalt. Aceste infecții repetate vor duce la formarea cicatricilor renale, iar copiii mici sunt consideraţi în mod particular mai vulnerabili de a dezvolta aceste sechele renale şi consecințele acestora (1). Astfel, în Marea Britanie, toți copiii cu vârsta sub 5 ani trebuie investigați după primul episod confirmat de infecție urinară $(2,3)$. Metodele imagistice sunt utilizate de rutină în stabilirea diagnosticului de reflux vezico-ureteral. În mod tradițional, retrocistografia micțională este cea mai frecventă metodă imagistică utilizată în vederea evidențierii refluxului vezico-ureteral, însă dezavantajul ei este reprezentat de expunerea la radiații, efect nedorit mai ales în cazul copiilor. De altfel, ghidurile mai recente nu recomandă de rutină efectuarea retrocistografiei micționale după primul episod de infecție febrilă a tractului urinar. Astfel, în scopul de a elimina acest efect nedorit, la mijlocul anilor '90 a fost propusă ecografia renală cu substanță de contrast ca fiind o metodă lipsită de iradiere, utilă pentru detectarea şi pentru monitorizarea copiilor cu reflux vezico-ureteral (4). Substanțele de contrast de primă generație conțin microbule stabile umplute $\mathrm{cu}$ aer, printre acestea Levovist ${ }^{\circledR}$ a fost singurul aprobat pentru utilizarea în pediatrie în câteva dintre țările europene (5). După aproximativ 10 ani, acesta a fost înlocuit de substanțele de contrast de generația a doua. Astfel, SonoVue® este o substanță de contrast de 
generația a doua care conține microbule stabile umplute cu gaz şi a fost eliberat pe piaţă la sfârşitul anului $2001(6,7)$. Metoda presupune în prima etapă introducerea unei sonde uretro-vezicale, pe care ulterior se va administra substanța de contrast urmată de urmărire ecografică. Astfel, refluarea microbulelor în ureter şi sistemul pielocaliceal poate fi decelată ultrasonografic. În funcție de aspectul ecografic al ureterului şi sistemului pielocaliceal prin măsurători ultrasonografice ale diametrelor acestora, se va stabili diagnosticul de reflux vezicoureteral, precum şi prezența hidronefrozei, putându-se estima gradul acestora.

\section{PREZENTARE DE CAZ}

Prezentăm cazul unei paciente, în vârstă de 3 ani, care s-a internat în clinica noastră cu suspiciunea unui reflux vezico-ureteral pentru investigații de specialitate şi recomandarea unui tratament adecvat. Antecedentele personale patologice au evidențiat 4 episoade de cistită acută tratată ambulator şi 3 episoade de infecție urinară de tip înalt, pentru care pacienta a fost spitalizată la nivel teritorial primind antibiotice intravenos, ultimul episod fiind în urmă cu aproximativ 3 luni, pentru care a primit tratament antibiotic intravenos, ulterior primind chimiopofilaxie antibiotică (Augmentin) până în momentul internării în clinica noastră.

Examenul obiectiv în momentul internării nu a evidențiat elemente patologice, G: $12,5 \mathrm{~kg}$. Analizele de laborator efectuate au fost în limite normale. Am efectuat, de asemenea, ecografie abdominală nativă, care nu a relevat modificări patologice. Astfel că am decis efectuarea ecografiei abdominale cu substanță de contrast de generație nouă - So-
noVue ${ }^{\circledR}$. După introducerea unei sonde uretro-vezicale, am introdus pe sondă substanța de contrast. În prima etapă, ultrasonografic s-a evidențiat umplerea completă a vezicii urinare, iar ulterior se vizualizează ureterele bilateral, mai dilatat pe partea dreaptă, aproximativ 6-7 mm diametru spre deosebire de partea stângă unde diametrul a fost de 4-5 mm (Fig. 1).

Astfel, s-a pus în evidență reflux vezico-ureteral bilateral. În următoarea etapă, pe partea dreaptă, s-a observat opacifierea completă a sistemului pielocaliceal al rinichiului drept, $\mathrm{cu}$ un pielon dilatat, măsurând aproximativ 18,5/10 mm (Fig. 2).

În partea stângă, evaluarea ecografică după introducerea de substanță de contrast a relevat opacifierea completă a sistemului pielo-caliceal al rinichiului stâng, însă cu dilataţii mai uşoare comparativ cu rinichiul drept, şi anume $10 / 7 \mathrm{~mm}$. În concluzie, evaluarea ecografică renală cu substanță de contrast a arătat reflux vezico-ureteral bilateral, estimat ca fiind de gradul 3 pe partea dreaptă, respectiv de gradul 2 pe partea stângă. În vederea evaluării funcției renale, am efectuat, de asemenea, scintigrafie renală cu acid dimercaptosuccinic (DMSA), care a arătat hipofuncție renală dreaptă, de $39 \%$, cu duplicitate a sistemului colector şi moderată dilataţie a pielonului superior. Rinichiul stâng a prezentat funcție normală, şi anume $61 \%$. De asemenea, dimensiunea rinichiului drept a fost mai mică decât a celui stâng, şi anume $62 \mathrm{~mm}$ comparativ cu $71 \mathrm{~mm}$. Scintigrafia cu DMSA a evidențiat, de asemenea, deficit de captare în $1 / 3$ superioară a rinichiului drept, fără a releva prezența de cicatrici renale.

Pe baza celor menționate mai sus, am stabilit diagnosticele de reflux vezico-ureteral bilateral şi ne-

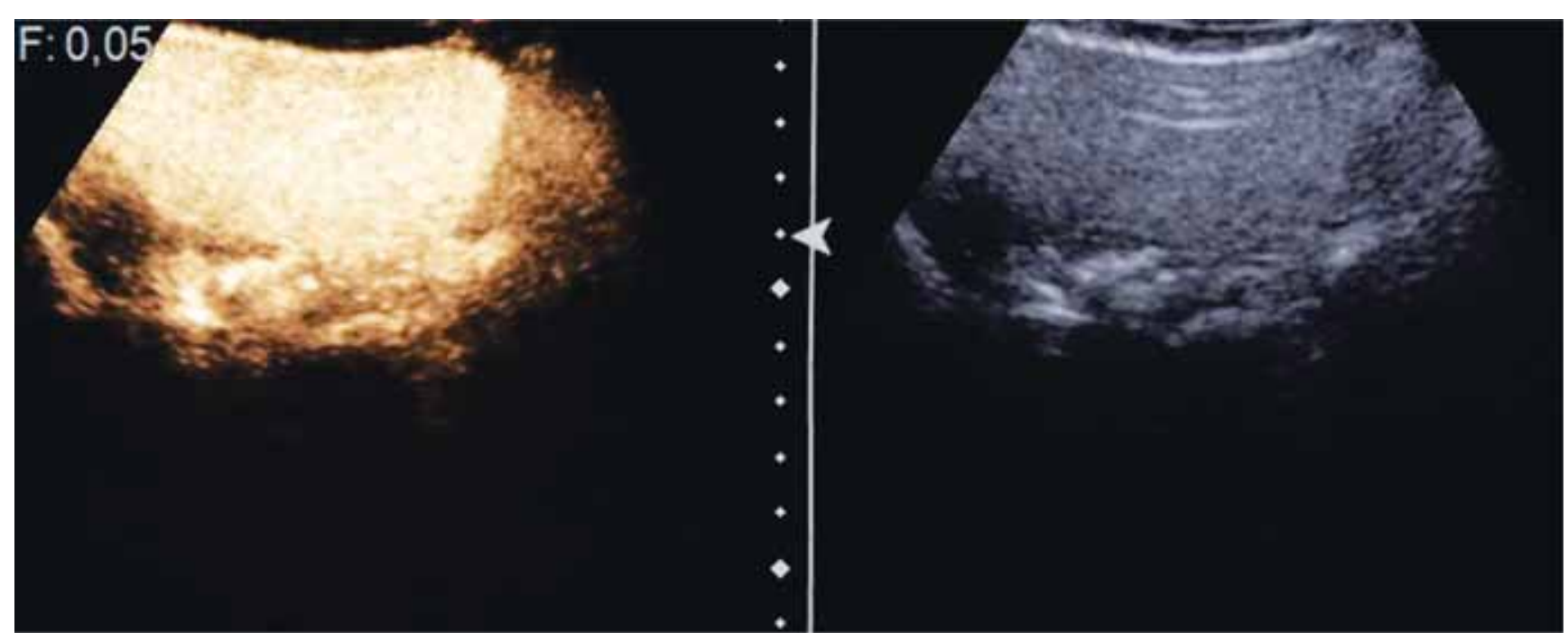

FIGURA 1. Aspectul vezicii urinare post-contrast cu evidențierea refluxului vezico-ureteral bilateral 


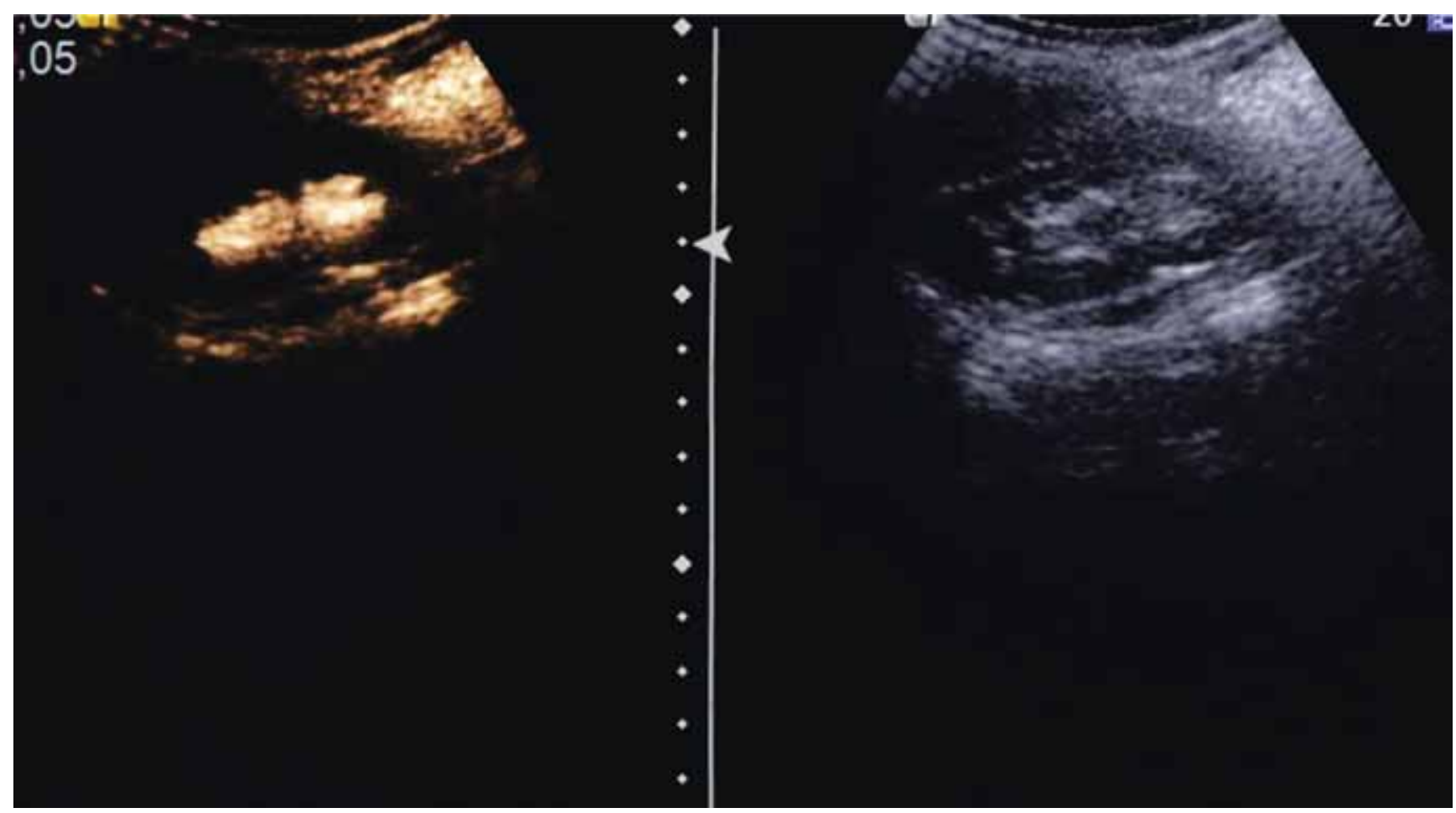

FIGURA 2. Rinichiul drept - aspect post-contrast

fropatie de reflux la nivelul rinichiului drept. Recomandările în momentul externării au constat în continuarea chimioprofilaxiei cu Augmentin suspensie a $400 \mathrm{mg} / 57 \mathrm{mg} / 5 \mathrm{ml}, 1,5 \mathrm{ml}$ seara, timp de o lună, urmat de sulfametoxazol suspensie a 40 $\mathrm{mg} / 5 \mathrm{ml}, 3 \mathrm{ml}$ seara, în următoarea lună, iar în a treia lună Cefalexin suspensie a $125 \mathrm{mg} / 5 \mathrm{ml}, 5 \mathrm{ml}$ în fiecare seară, cu repetarea schemei pe termen lung. De asemenea, am recomandat reevaluare periodică a refluxului vezico-ureteral prin ecografie cu substanță de contrast anual, precum şi consult nefrologic o dată la 6 luni, sau mai repede, în caz de febră sau simptomatologie sugestivă pentru infectie de tract urinar.

Particularitatea cazului constă în diagnosticarea unui reflux vezico-ureteral bilateral prin ecografie cu substanță de contrast la o pacientă cu multiple infecții de tract urinar în antecedente, la care ecografia renală nativă nu a evidenţiat modificări patologice.

\section{DISCUȚII}

Infecțiile de tract urinar reprezintă o patologie cu o frecvență crescută la vârsta pediatrică, iar unul dintre cei mai des întâlniţi factori implicați în patogeneza acestora este refluxul vezico-ureteral, fiind considerat a fi asociat în majoritatea cazurilor cu infecția de tract urinar (8). Refluxul vezico-ureteral este asociat în aproximativ $25-40 \%$ dintre cazuri cu infecțiile de tract urinar la copii, fără diferențe semnificative între cele două sexe, cu excepția perioadei de sugar (9). În această perioadă, sexul feminin este mai frecvent afectat. Astfel, a fost demonstrat că în perioada de sugar, refluxul vezico-ureteral este prezent la aproximativ $30 \%$ dintre băieții şi $43 \%$ dintre fetele care se prezintă cu infecție de tract urinar simptomatică (10). Cazul prezentat de noi este, de asemenea, de sex feminin, cu toate că nu este în perioada de sugar, fiind vorba de o pacientă în vârstă de 3 ani. Acest reflux vezico-ureteral nu este legat doar de lungimea anormală a ureterului intravezical, ci reprezintă, de asemenea, o problemă disfuncțională, caz în care pacienții pot prezenta şi tulburări de golire a vezicii urinare sau disfuncții intestinale (11). Cu toate acestea, există şi cazuri în care disfuncția vezicală poate reprezenta cauza refluxului vezico-ureteral. Pacienta prezentată mai înainte nu a prezentat nici una dintre aceste asocieri. Chiar dacă multe studii dintre trecut au considerat că refluxul vezico-ureteral este întotdeauna asociat cu nefropatie de reflux şi cicatrici renale (12), se pare că în prezent există date contradictorii atât referitoare la rolul refluxului vezicoureteral în apariția infecției de tract urinar (13), cât şi la efectul chimioprofilaxiei în prevenirea pielonefritei şi a cicatricilor renale (14). Cu toate acestea, în cazul pacientei noastre, a fost diagnosticat atât reflux vezico-ureteral bilateral, cât şi nefropatie de reflux la nivelul rinichiului drept. 
Cele mai frecvent folosite metode sunt retrocistografia micțională pentru detectarea refluxului vezico-ureteral şi scintigrafia renală cu DMSA pentru localizarea infecției şi detecția sau prezicerea unei eventuale cicatrici renale. Dezavantajele majore ale acestor două tehnici sunt reprezentate de iradierea pacientului şi de minima invazivitate pe care o presupun. $\mathrm{Cu}$ toate acestea, iradierea este mult mai redusă în cazul scintigrafiei cu DMSA, preconizându-se extinderea metodei în detrimentul retrocistografiei micționale. Astfel, în scopul de a elimina aceste două inconveniente, precum şi din cauza faptului că frecvența acestei patologii este mare la vârsta pediatrică, s-a recurs la ultrasonografia renală cu substanță de contrast. Iniţial s-au utilizat agenți de contrast de primă generație, însă în prezent există pe piață agenții de generația a doua, precum SonoVue ${ }^{\circledR}$, care datorită gazului conținut în microbule poate fi utilizat şi pentru evaluarea sistemului urinar, aceste bule putând fi detectate ultrasonografic şi la nivelul căilor urinare (15). De asemenea, datorită fragilității mai scăzute a microbulelor conținute de agenții de contrast de generația a doua, durata în care aceştia pot fi detectați ultrasonografic este mai mare (15). SonoVue ${ }^{\circledR}$ a fost evaluat în mai multe studii recente. Astfel, conform unui studiu care a vizat mai multe instituții de radiologie din Europa, aproximativ 4.131 de copii au fost supuşi ultrasonografiei cu substanță de contrast prin administrare intravezicală de SonoVue ${ }^{\circledR}$, fără a fi decelat vreun efect advers care să se datoreze doar administrării acestei substanțe de contrast (16). Cu toate acestea, există anumite simptome care au fost raportate de către pacienți după această procedură, şi anume disurie, retenție urinară, durere abdominală tranzitorie, creşterea frecvenței micțiunilor, secreții uretrale cu sânge sau mucus, anxietate sau plâns în timpul micțiunii, vărsături, iritație perineală sau infecție de tract urinar (4). Aceste simptome nu doar că sunt relativ rare, dar au fost descrise şi în cazul celorlalte proceduri imagistice utilizate pentru diagnosticul refluxului vezico-ureteral şi sunt datorate cel mai probabil cateterizării vezicii urinare, nefiind legate de administrarea de substanță de contrast.

Metoda ultrasonografiei cu substanță de contrast pentru depistarea refluxului vezico-ureteral este superioară metodelor imagistice tradiţionale, fiind o metodă minim invazivă şi lipsită de riscul iradierii pacientului, însă această metodă, spre deosebire de cistografia micțională, nu poate preciza $\mathrm{cu}$ exactitate gradul refluxului vezico-ureteral. $\mathrm{Cu}$ toate acestea, principala limitare a acestei metode este că nu pot fi vizualizate simultan atât uretra, cât şi sistemul reno-ureteral în comparație cu metodele imagistice tradiționale. De asemenea, asocierea acestei metode cu un risc crescut de infecție urinară asociată cateterizării este un alt dezavantaj, care a fost raportat a fi de până la $80 \%$ în cazul cateterizării vezicii urinare pe termen scurt $(17,19)$.

Majoritatea ghidurilor recomandă de primă intenție retrocistografia micțională pentru precizarea gradului refluxului, ecocistografia micțională fiind metoda de urmărire a refluxului. $\mathrm{Cu}$ toate acestea, cazul prezentat de noi ar putea pune în discuție utilizarea ecocistografiei micționale de primă intenție la pacienții cu repetate infecții de tract urinar ca alternative a retrocistografiei micționale cu substanță de contrast, însă fără a fi o recomandare categorică.

\section{CONCLUZII}

Ultrasonografia cu substanță de contrast, utilizând agenții de generația a doua, pentru diagnosticarea refluxului vezico-ureteral reprezintă o metodă relativ uşor de efectuat, eficientă, minim invazivă, lipsită de iradiere. Această metodă este foarte utilă în cazul pacienţilor de vârstă pediatrică care prezintă infecții de tract urinar repetate.

Conflict of interest: none declared Financial support: none declared 